\title{
Corporate memory in the lean context
}

\author{
Preventing short- andlong-term information loss
}

\author{
Nuno Sobral ${ }^{1}$, Beatriz Rodrigues ${ }^{1}$, Cláudia Serra ${ }^{1}$, Nuno Bastos ${ }^{1}$, Adriana Gomez ${ }^{1}$, Catarina Mequita ${ }^{1}$, Maria \\ Oliveira $^{1}$, Tiago Pacheco ${ }^{1}$, Ivo Pinheiro ${ }^{1}$, Lúcia Silva ${ }^{1}$, Senhorinha Teixeira ${ }^{1,2}$, José Dinis-Carvalho ${ }^{1,2}$ \\ ${ }^{1}$ Department of Production and Systems Engineering \\ ${ }^{2}$ Centro ALGORITMI \\ University of Minho \\ Guimarães, Portugal \\ a73996@alunos.uminho.pt \\ \{st,dinis\}@dps.uminho.pt
}

\begin{abstract}
A large part of the information necessary for an organization to function is stored exclusively in people's memories. This applies to two different kinds of information - short-term information related to daily operations in the shop floor as well as long-term accumulated knowledge and expertise.
\end{abstract}

In the present article we propose several solutions for preventing short- and long-term information loss in an industrial setting. We analyze information loss and its consequences at an automotive component factory in the North of Portugal.

For the short-term information loss, we propose lean tools such as gravity flow racks, kanban and andon screens. For long-term information loss, we propose the implementation of mentorship programs, the creation of a knowledge repository based on wiki technology and the use of explanatory labels.

Keywords - corporate memory; knowledge-based economy; mentoring; wiki; lean

\section{INTRODUCTION}

This article was developed as a part of a PBL (Project Based Learning) programme of the Integrated Master in Industrial Engineering and Management carried out from September 2018 to January 2019. The aim of this programme is to facilitate engineering students' interaction with industrial companies and enable them to apply what they have learned in academia in a professional context. The project is supported by five courses of the 7 th semester [1], [2]. Students form groups and a different company is assigned to each one.

The idea for this article came about early on during the course of our project at an automotive parts factory in northern Portugal, henceforth referred to as 'the Factory'. A common theme we found across a diverse set of problem areas was information loss caused by people keeping information only in their heads. When we discussed our observation with the Factory's Lean Manager, we were met with whole hearted agreement - he called it the problem of 'human computing'.

We propose that the phenomenon of employees storing information exclusively in their memories can be divided into two main categories, according to their short- or long-term relevance. Short-term information relates to everyday operations on the shop floor, e.g. which of several parts was processed first.
Long-term information denotes accumulated knowledge and expertise, e.g. how to repair a given machine or how to negotiate with clients.

According to Alves [3], lean "is about "doing more with less" where less means less space, less stocks, less human effort, less materials, less energy, less of everything.' Lean has been used to solve a diverse set of problems that modern industry faces. So, we were keen to apply it to information management. For short-term information we propose solutions based on lean tools such as kanban systems, andon screens and gravity flow racks.

For long-term information we propose the implementation of mentoring programmes and the creation of a knowledge repository using wiki technology and attach explanatory labels to equipment.

Throughout this article, the reader will find a number of concrete examples from the Factory which will hopefully serve to illustrate and contextualize our points. We have gathered these examples through direct observation and extensive discussions with employees from different departments.

\section{SHORT-TERM LOSS OF INFORMATION}

\section{A. Overall description}

Short-term information loss regards information that is created and needed during the course of little more than one day, often one hour, especially information related to shop-floor operations. It occurs mainly when workers end their shift, change to a different workstation or have to interrupt their work. Workers keep a large amount of information about parts (raw materials, subassemblies and finished products), defective products, machines and tools in their memories. Examples are the arrival time of parts, their location at a given time, the placement of tools, which components need replenishment and which approaches for solving a machine malfunction have already been tried. Since this information is not recorded anywhere else, whenever the worker steps away from his workstation the information leaves with him. As we will see below, the loss of this information can waste time, cause quality problems, and disrupt the production flow. 


\section{B. Lean solutions}

In this section, we describe solutions for three problems of short-term information loss we encountered at the Factory, all of them based on lean tools. Table 1 provides an overview of those solutions as well as their goals and an example of the kind of question they answer.

TABLE I. SOLUTIONS FOR SHORT-TERM INFORMATION LOSS

\begin{tabular}{|l|l|l|}
\hline \multicolumn{1}{|c|}{ Solution } & \multicolumn{1}{c|}{ Goal } & \multicolumn{1}{c|}{ Question } \\
\hline $\begin{array}{l}\text { Gravity flow } \\
\text { racks }\end{array}$ & FIFO & Which component was here first? \\
\hline Kanban & $\begin{array}{l}\text { Material } \\
\text { replenishment }\end{array}$ & $\begin{array}{l}\text { How many units of component A } \\
\text { are needed at workstation B and } \\
\text { when? }\end{array}$ \\
\hline Andon screens & $\begin{array}{l}\text { Avoiding } \\
\text { duplicate work }\end{array}$ & $\begin{array}{l}\text { Machine X isn't working as it } \\
\text { should. Have we tried to doing } Y \\
\text { yet? }\end{array}$ \\
\hline
\end{tabular}

\section{1) Gravity flow racks}

Let us start with an example from the Factory. After an operation where varnish is applied to a component, the worker keeps in mind which piles of trays are older and shares that information with the colleague who transports the trays to keep older trays from lingering for too long. This current procedure brings about numerous disadvantages. It does not guarantee perfect First In First Out (FIFO) storage, because the colleague picks the top trays in the pile first and the bottom trays may stay there for an indefinite amount of time, thus jeopardizing the quality. This problem turns even more serious when workers change their shift and take all information with them.

Issues like the above can often be solved in surprisingly simple ways. A gravity flow rack, where trays are inserted at the top and roll down as older ones are removed from the bottom [4], ensures reliable FIFO storage even across shifts. Since workers no longer have to remember which trays are newer and which ones are older, the system becomes error-proof. Potentially even other errors may be reduced, since workers now have to deal with a lighter cognitive load. Similar racks can also be used to keep track of defects, for example. [5, p. 122].

2) Kanban

Poor inventory timing — parts arriving too early or too late due to missing or incorrect information - causes unpredictability and waste in the form of time and inventory [6, p. 479]. A move (or conveyance) kanban can be used to trigger material replenishment only when needed, keeping inventory levels and work-in-progress under control [7]. The trigger signals to the previous station that material can be withdrawn from the inventory and transferred to the next station. Triggers come in many forms - including cards, color-coded spheres, kanban squares and container-as-kanban. Kanban squares are marked spaces on the shop-floor or on work benches drawn to fit one or several parts; replenishment is triggered by an empty square. Container-as-kanban means that the empty container acts as the signal [6, p. 480].
This latter solution is already implemented at the Factory. Workstations have two boxes for every component. When one of them is empty it constitutes the signal to refill it without compromising the workflow. We propose they could go one step further by implanting a so-called 'dual-card system' wherein the move kanban used for material replenishment would be complemented by a production kanban that triggers the production of a new part and thus established a pull production system.

\section{3) Andon screens}

Visual Management attempts to improve the performance of an organization using visual stimuli to communicate important information at a glance [8].

The Factory uses andon screens to display where malfunctions are occurring. As it stands, different workers often try the exact same repair procedures over and over again during the course of a day, because previous procedures are often not communicated between teams.

A first step towards fixing this problem would be to show on the display how many times that specific machine has malfunctioned in the last 24 hours. Furthermore, we discussed the possibility of equipping workers with tablets that allow them to consult a machines individual repair history as they approach it.

\section{LONG-TERM LOSS OF KNOWLEDGE}

\section{A. Overall description}

Brown and Duguid [9, p. 115] point out that if NASA wanted to go to the moon again, it would have to start from scratch, having lost not the data, but the human expertise that took it there last time'. This highlights the importance of knowledge management. Today's economy is knowledgebased, i.e. it relies more on intellectual capabilities than on physical inputs or natural resources [10], making knowledge a crucial competitive edge [11]. Therefore, it is our view that better methods for capturing, retaining and transmitting knowledge need to be set in place.

Unlike short-term term loss of information, long-term loss of knowledge is more closely linked with employee attitudes. Employees often do not document their knowledge about processes and procedures. When they walk out (be it due to sick leave, days off or, more permanently, due to promotions or retirement) the knowledge they have accumulated through experience often walks out with them [12]. It is important to consider this issue in the light of the frequent change of employment we observe today - the U.S. Bureau of Labor of Statistics [13] records a median employee tenure of just 4.2 years. According to Maier [14, p. 27] 'the degree to which knowledge in organizations is stored mainly in its individual members is indicated by research on the effects that turnover has [on] learning processes and information-processing'.

So why don't employees write their knowledge down? Obviously, doing so takes time. However, that is not the only reason. Experts often fear losing their status in the company by 
documenting the expertise they have acquired. [12]. According to Suzaki [5, p. 142] 'some of the most difficult [challenges] are $[\ldots]$ internal constraints such as people feeling insecure about giving away their knowledge to others' .

\section{B. Creating a Corporate Memory}

Much can be learned from mistakes. However, mistakes are often expensive, so it would make sense to learn as far as possible from one's predecessors' mistakes rather than from one's own. Thus, it would be in organizations' interest to be able to accumulate knowledge gained from previous failures and, of course, successes across time, even as people come and go.

Efforts towards flattening hierarchies have actually exacerbated the problem of memory loss, since functional groups centred around a technical leader have become less common [12]. Quintas [15, p. 5] describes how, starting the 1980s, many European and North American organizations underwent downsizing, de-layering (shedding layers of middle management) and outsourcing programmes. With fewer managers, those remaining will inevitably be responsible for larger departments and less familiar with technical details. Accordingly, these bloodletting strategies resulted in the loss of their corporate memories, making it difficult for the affected organizations to react to new paradigms and challenges.

In the following subsections we propose three solutions for preserving knowledge in the long term: a knowledge repository based on wiki technology, mentoring programmes and physical labels in the shop floor. Fig. 1 provides an overview.

\section{1) Knowledge repository and wiki:}

Companies may use a type of software known as CMS (Content Management System) to implement a knowledge repository. Employees will then be encouraged (through recognition or financial incentives) and given time to introduce new information into the knowledge repository, their contributions going through a review process by peers or supervisors [12].

The knowledge repository should contain best practices regarding safety and process engineering, manufacturers' manuals for the factory's machines (together with additional details which the engineering department considers necessary to include). Quality should take precedence over quantity. 'Knowledge repositories [...] are not dumping grounds for every thought anyone in the organization has ever had. They should be containers for knowledge that the organization [...] considers important and potentially useful to others.' $[16$, p. 76]

We propose that the CMS of the knowledge repository should be a wiki. This conclusion was reached primarily because of dependable nature as well as the distinctive features and philosophy of wikis.

Wikis have been around for more than 20 years, are widely used and actively being developed as open-source software [17]. Indeed, a variety of wiki engines are accessible for free, eliminating the need for expensive and cumbersome software licenses.

Prasarnphanich and Wagner [18] highlight four unique characteristics of the wiki:

Collective authorship - Wikis enable web documents to be authored collectively without individual ownership of the documents. Users can edit the pages of others and their version replaces the previous one.

Instant publication - As soon as an author submits his contribution, it becomes visible to the whole community without going through a previous review. This encourages pride of authorship and enables other members to quickly build upon that first contribution.

Versioning - Prior versions of a page are kept in a temporal database, as are the date and author associated with each edit. This facilitates rollback, comparison and difference

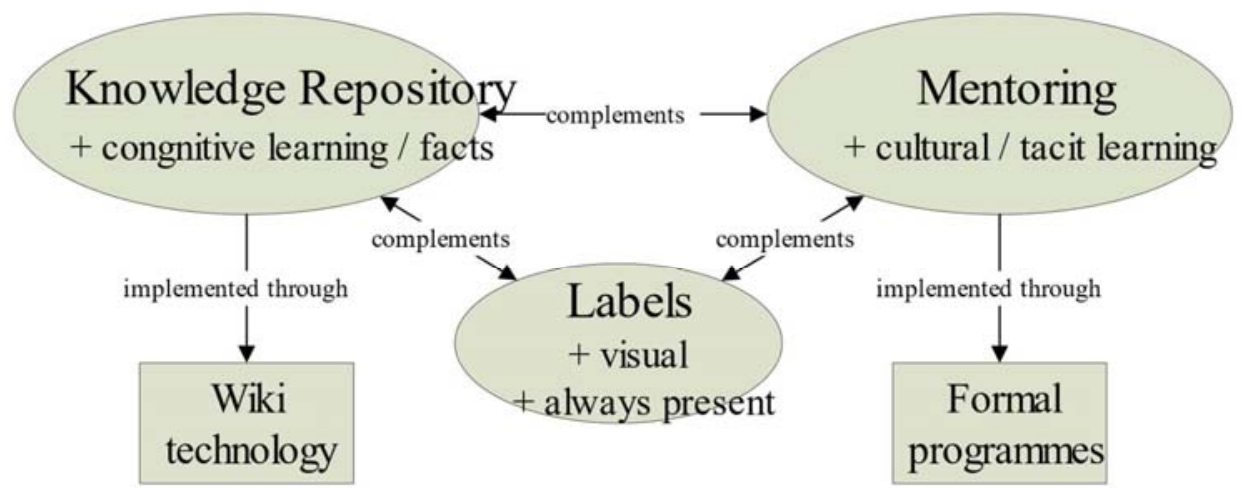

Figure 1 Solutions for long-term loss of knowledge 
identification, thus also acting as a safeguard against mistaken edits.

Simplicity of authorship - Wikis make it easy to write new content since they do not require any web publishing skills on the user's part. Authors can just type in plain text and linking to related content is straightforward.

Wikis have entered the workplace in force, finding a use in sectors as diverse as technology, government and pharmaceutical [17]. The implementation of a workplace wiki is often a grassroots initiative on the part of a single employee or a small group, however management support and guidance is necessary to align the wiki with the organization's strategy [17], [19]. Moreover, while instant publication is key for dynamizing contributions to the wiki, quality control can and should be done after the fact.

The Factory's executives told us that they had been keen on implementing a knowledge repository for some time, but were they unsure of how to go about it. Moreover, they stressed that, in keeping with lean thinking, adding to the corporate memory should not constitute an additional burden. Instead existing workflows and artefacts can be integrated into the new knowledge management approach. In particular, the information already present in emails, reports, A3 problem solving sheets and the Factory's malfunction and repair tracking system should easily be added to the knowledge repository.

We believe workplace safety and machine repairs are among the areas that could benefit most from the implementation of a knowledge repository at the Factory:

The Factory's Human Resources department is responsible for all work-related incidents and accidents. Once an analysis into the root causes has taken place, HR decides on the necessary corrective actions and writes up a report. These reports are stored in a computerized system. While this system integrates several factories in different locations thus allowing knowledge transfer across space, there is no easy way to search for incidents of a particular type, which would facilitate knowledge transfer across time. Using the knowledge repository, a particular area of concern could be researched on a keyword basis, revealing what actions have been taken in the past at any of the factories.

While the Factory uses a digital system to track malfunctions and repairs, information in the tracking system is difficult to access, available only to a small number of employees and automatically deleted after one year. Having the same information stored in an easily accessible and actionable format would make it much more useful and conducive towards longterm learning.

Knowledge repositories promote cognitive learning (pertaining to knowledge that can be expressed in formal and systematic language) rather than culture learning or the adoption of implicit knowledge [20, p. 780]. Thus, it is necessary to complement them with mentoring programs.

\section{2) Mentoring programs:}

Mentoring programmes can be a part of the answer since having older workers acting as mentors towards younger ones fosters the transmission of knowledge. While such programmes are limited in scope as they primarily serve to ease inexperienced employees into their new positions [21], they are crucial for transmitting knowledge that is idiosyncratic or difficult to articulate (cf. [22] on 'tacit knowledge'). Mentoring has been shown to provide both career and psychosocial benefits for mentees (or protégés) [23].

While mentoring relationships often develop spontaneously, many companies have started to implement formal assigning of mentors and mentees to one another. Although mentors and mentees identify more with each other in informal relationships, formal programmes drive mentees to become more goal-oriented and proactive [23].

\section{3) Physical labels:}

In the Factory we observed that some of the machines are called by different designations by older and younger employees. More importantly, we often received conflicting information about the production process. For example, in regard to the above-mentioned varnishing process, some employees claimed the components left the varnishing machine already fully dry; other that they take another 30 minutes to fully dry. This has direct implications on production flow.

The Factory placed andon light towers on top of many machines to signal and help identify problems that may compromise or halt production. However, workers, engineers and maintenance technicians did not know what many of the colour combinations meant or often even where the machines' manuals containing this information could be found.

We propose simple labels attached to the machines showing their name and how to operate them, as well as a legend of what each colour on the andon lights stands for.

\section{CONCLUSIONS}

To sum up, information should not be stored in people's minds, at least not exclusively. There are relatively simple, even purely mechanical, solutions for lessening the reliance on human memory on a short-term basis. In the long term, we propose the creation of a digital knowledge repository, in the form of a wiki, the implementation of mentoring and the application of physical labels in order to capture and pass down expertise.

In the future we hope to accompany the implementation of our proposals at the Factory. We aim for this article to become a pertinent contribution towards helping organizations minimize human error, retain knowledge and adapt to today's knowledge-based economy. 
Drafting this article allowed us to understand that our scope of action as industrial engineers is not limited to using any specific tool or technique. On the contrary we can and must look at organizations holistically and see information and knowledge management as a vital asset for accomplishing our work.

\section{ACKNOWLEDGMENT}

This work has been supported by the Portuguese Foundation for Science and Technology (FCT) within the Project Scope UID/CEC/00319/2019 (ALGORITMI Center).

\section{REFERENCES}

[1] R. M. Lima et al., Ten years of project-based learning (PBL) in industrial engineering and management at the University of Minho. 2017.

[2] R. M. Lima, D. Carvalho, L. C. de Campos, D. Mesquita, R. M. Sousa, and A. C. Alves, "Projects with the industry for the development of professional competences in industrial engineering and management," in Project Approaches in Engineering Education, 2014

[3] A. C. Alves, M. F. Abreu, A. P. Tereso, and P. V. Ferreira, "Production system configuration selection in a lean environment using analytic hierarchy process," Nova Science Publishers, Inc., 2017.

[4] N. H. A. Halim, A. Jaffar, N. Yusoff, and A. N. Adnan, "Gravity Flow Rack's Material Handling System for Just-In-Time (JIT) Production," Procedia Eng., vol. 41, pp. 1714-1720, Jan. 2012.

[5] K. Suzaki, The new shop floor management: empowering people for continuous improvement. New York: The Free Press, 1993.

[6] N. Slack, S. Chambers, and R. Johnston, Operations Management, 5th ed. Harlow: Prentice Hall, 2007.

[7] J. Puche, J. Costas, B. Ponte, R. Pino, and D. de la Fuente, "The effect of supply chain noise on the financial performance of Kanban and Drum-Buffer-Rope: An agent-based perspective," Expert Syst. Appl., vol. 120, pp. 87-102, Apr. 2019.

[8] L. P. Steenkamp, D. Hagedorn-Hansen, and G. A. Oosthuizen, "Visual Management System to Manage Manufacturing Resources," Procedia Manuf., vol. 8, pp. 455-462, Jan. 2017.

[9] J. S. Brown and P. Duguid, The Social Life of Information. Boston, MA: Harvard Business Review Press, 2017.

[10] W. W. Powell and K. Snellman, "The Knowledge Economy," Annu.
Rev. Sociol., vol. 30:199-220, 2004

[11] C. C. Huang, Y. N. Fan, C. C. Chern, and P. H. Yen, "Measurement of analytical knowledge-based corporate memory and its application,” Decis. Support Syst., 2013.

[12] J. Chosnek, "Maintaining the corporate memory," J. Loss Prev. Process Ind., 2010

[13] U.S. Bureau of Labor of Statistics, "Employee Tenure Summary," 2018. [Online]. Available: https://www.bls.gov/news.release/tenure.nr0.htm. [Accessed: 27Dec-2018].

[14] G. W. Maier, C. Prange, and L. von Rosenstiel, "Psycological Perspectives on Organizational Learning," in Handbook of Organizational Learning and Knowledge, M. Dierkes, A. B. Antal, J. Child, and I. Nonaka, Eds. Oxford: Oxford University Press, 2001, p. 27.

[15] P. Quintas, "Managing knowledge in a new century," in Managing knowledge: An essential reader., P. Quintas and T. Ray, Eds. London: Sage Publications, 2005, pp. 1, 5.

[16] W. R. Bukowitz and R. L. Williams, The Knowledge Management Fieldbook. Great Britain: Financial Times Pretice Hall, 1999.

[17] C. Standing and S. Kiniti, "How can organizations use wikis for innovation?," Technovation, 2011.

[18] P. Prasarnphanich and C. Wagner, "The role of wiki technology and altruism in collaborative knowledge creation," J. Comput. Inf. Syst., 2009.

[19] O. Díaz and G. Puente, "Wiki Scaffolding: Aligning wikis with the corporate strategy," in Information Systems, 2012.

[20] P. Pawlowsky, J. Forslin, and R. Reinhardt, "Practices and Tools of Organizational Learning," in Handbook of Organizational Learning and Knowledge, M. Dierkes, A. B. Antal, J. Child, and I. Nonaka, Eds. Oxford: Oxford University Press, 2001, p. 780.

[21] W. Heisler and D. Bandow, "Retaining and engaging older workers: A solution to worker shortages in the U.S.," Bus. Horiz., 2018.

[22] I. Nonaka and H. Takeuchi, "The knowledge-creating company: How Japanese companies create the dynamics of innovation," Long Range Plann., 1999.

[23] C. R. Wanberg, J. Kammeyer-Mueller, and M. Marchese, "Mentor and protégé predictors and outcomes of mentoring in a formal mentoring program," J. Vocat. Behav., no. 69, pp. 410-423, 2006. 